\title{
Hopping conduction mechanism and impedance spectroscopy analyses of \\ La0.70Sr0.25Na0.05Mn0.70Ti0.3003 ceramic
}

zeineb raddaoui

Université de Monastir: Universite de Monastir

elkossi safwen

Université de Monastir: Universite de Monastir

alex Trukhanov

SSPA Scientific-Practical Materials Research Centre of NAS of Belarus: GO Naucno-prakticeskij centr Nacional'noj akademii nauk Belarusi po materialovedeniu

alex Kozlovskiy

Kazakhstan Nuclear University

M Zdorovets

Kazakhstan Nuclear University

jemai dhahri $(\nabla$ j.dhahri3000@gmail.com )

Universite de Monastir faculte of sciences https://orcid.org/0000-0002-3045-7285

\section{Research Article}

Keywords: Perovskite, Relaxation process, Oxygen vacancies, Impedance spectroscopy

Posted Date: February 23rd, 2021

DOl: https://doi.org/10.21203/rs.3.rs-236987/v1

License: (9) This work is licensed under a Creative Commons Attribution 4.0 International License.

Read Full License 


\title{
Hopping conduction mechanism and impedance spectroscopy analyses of $\mathrm{La}_{0.70} \mathrm{Sr}_{0.25} \mathrm{Na}_{0.05} \mathrm{Mn}_{0.70} \mathrm{Ti}_{0.30} \mathrm{O}_{3}$ ceramic
}

Z. Raddaoui ${ }^{\text {a }}$, S. El. Kossi ${ }^{\text {a }}$, A.V. Trukhanov ${ }^{\text {b,c,d }}$, A.L. Kozlovskiy ${ }^{\text {e }}$, M.V. Zdorovets e,f,g , J. Dhahri ${ }^{a^{*},}$

${ }^{a}$ Laboratoire de la Matière Condensée et des Nanosciences, Université de Monastir, Faculté des Sciences de Monastir, Avenue de l'environnement 5019 Monastir, Tunisie.

${ }^{b}$ Scientific-Practical Materials Research Centre of NAS of Belarus, P. Brovki str., 19, 220072 Minsk, Belarus.

${ }^{c}$ South Ural State University, Lenin av., 76, 454080 Chelyabinsk, Russia

${ }^{d}$ National University of Science and Technology MISiS, Leninsky av., 4, 119049 Moscow, Russia

e The Institute of Nuclear Physics, Almaty 050032, Kazakhstan

${ }^{\mathrm{f}}$ L.N. Gumilyov Eurasian National University, Nur-Sultan 010008, Kazakhstan

${ }^{\mathrm{g}}$ Ural Federal University named after the First President of Russia B.N. Yeltsin, 620075 Yekaterinburg, Russia

*Corresponding author: E-mail address: j.dhahri3000@gmail.com

\begin{abstract}
The perovskite sample $\mathrm{La} 0.7 \mathrm{Sr}_{0.25} \mathrm{Na} 0.05 \mathrm{Mn}_{0.7} \mathrm{Ti}_{0.3} \mathrm{O}_{3}\left(\mathrm{LSNM}_{0.70} \mathrm{~T}_{0.30}\right)$ was produced via a solidstate route process. Impedance spectra of $\mathrm{LSNM}_{0.70} \mathrm{~T}_{0.30}$ in the frequency interval $[40 \mathrm{~Hz}-$ $1 \mathrm{MHz}]$ were studied at several temperatures $[80 \mathrm{~K}$ to $440 \mathrm{~K}]$. The ac conductivity ( $\sigma_{\mathrm{ac}}$ ) established that according to the Jonscher law. $\sigma_{\text {ac }}$ is described by Non-overlapping Small Polaron Tunneling model at low temperatures and Correlated Barrier Hopping model at high temperatures. From dc conductance analysis, conduction seems to be thermally activated, suggesting the existence of semiconductor process. Detailed investigation of impedance data revealed the non-Debye nature of the relaxation processes in the sample. In addition, Dielectric constant curves were applied to examine the relaxation dynamics of charge carriers. In fact, the Debye-like relaxation was performed on the basis of the polarization of spatial charges following Maxwell-Wagner model and Koop's phenomenological theory.
\end{abstract}

Keywords: Perovskite, Relaxation process, Oxygen vacancies, Impedance spectroscopy.

\section{Introduction}


Demand for powerful nanotechnology application is generating challenge among scientists and engineers to provide a stable and flexible system. In fact, more compounds have been suggested in this context and some perfection was achieved in various study fields by the perovskite system, for example, magneto-tunable photocurrent activity, Spin Hall-Magnetoresistive devices and electrocatalytic activity [1-3].

Perovskite manganese oxide with an $\mathrm{AMnO}_{3}$ general formula may be the next-generation sample for clean energy and large-scale energy storage due to its dual feature of magnetic/ electric properties and its diverse applications [4,5]. Its multiferroic nature demonstrates the strong influence of its morphological characteristics on the magneto-transport behavior explained in the framework of Zener's theory [6, 7].

However, manganite exhibits an important effect known as colossal magneto-resistance (CMR) closely related to its magnetic transition between a paramagnetic/insulating phase and ferromagnetic/metal phase [8-10]. The insulator-metal transition is due to the partial doped of the Rare Earth (RE) site by Alkaline Earth (AE) ions, causing the manganese ions to be trained in a combination of $\mathrm{Mn}^{3+} / \mathrm{Mn}^{4+}$ ions. It was thought that spin system and magneto-transport characteristics are related by the double exchange interaction caused by the motion of the $\mathrm{e}_{\mathrm{g}}$ electrons for $\mathrm{Mn}^{3+} / \mathrm{Mn}^{4+}$ ions [11-14]. The mixed valence state of manganese $\left(\mathrm{Mn}^{3+} / \mathrm{Mn}^{4+}\right)$ of these compounds displays the prominent role to alternate.

S. El Kossi et al. [15] explore the effect of incorporating a compound to affect the electrical characteristics, i.e. the connection between the electrical and the chemical characteristics. This variation in the conductivity value can be explained by morphological and the random distribution of cations in the lattice by raising concentration of the oxygen vacancy $\left(V_{0}\right)$, resulting from the effects of the charge compensation produced via the incorporation of ( $\mathrm{Sr}$, $\mathrm{Na}$ ) ions into the La-site and $\mathrm{Ti}$ ion into site $\mathrm{Mn}$ for $\mathrm{LaMnO}_{3}$.

In the present investigation, we report on the conduction process, the electrical characteristics and the behavior of the relaxation process of $\mathrm{LSNM}_{0.70} \mathrm{~T}_{0.30}$ ceramic synthesized via the solid state process. In addition, we discuss the conduction mechanism and dielectric relaxation determined by impedance spectroscopy (IS), showing the low acquired dielectric loss.

\section{Experimental procedure}

In this work, the sample $\mathrm{LSNM}_{0.70} \mathrm{~T}_{0.30}$ was produced by the solid state process reported in the previous research [16]. The precursors of metals $\mathrm{La}_{2} \mathrm{O}_{3}, \mathrm{SrCO}_{3}, \mathrm{Na}_{2} \mathrm{O}_{3}, \mathrm{TiO}_{2}$ and $\mathrm{MnO}_{2}$ (all Aldrich makes 99.99\%). The synthesis procedure is (stepwise) given in Fig.1. 
The X-ray pattern after the Rietveld refinement is examined in the previous paper [16]. Note that $\mathrm{LSNM}_{0.70} \mathrm{~T}_{0.3}$ crystallizes in rhombohedral (R-3c) pattern with no visible secondary phase, with lattice parameters $a=b=5.536$ (3) $\AA, c=13.438$ (3) $\AA$ and cell volume $V=356.75$ (2) $\AA^{3}$. The dielectric data were derived from ceramic disks after depositing gold electrodes on the circular faces by cathodic sputtering via an IS data employ an N4L-NumetriQ type PSM1735.

\section{Results and discussion}

\subsection{Conductivity analysis}

The conductivity spectra $\sigma(\omega)$ of the $\mathrm{LSNM}_{0.70} \mathrm{~T}_{0.30}$ compound at various temperatures over the wide frequency interval are illustrated Fig. 2(a). In the lower frequency range, the $\sigma(\omega)$ increased with the rise of temperature. The $\sigma(\omega)$ against frequency data exhibited more model properties such as dispersion, low frequency plateau and high frequency dispersion. The change in the $\sigma(\omega)$ slopes was found in the lower and higher frequency areas. The apparent low frequency plateau is frequency independent that correlates to the dc conductivity $\left(\sigma_{\mathrm{dc}}\right)$ and reveals long-distance mobility of the charge carriers. This low frequency plateau rose with increasing temperature, causing long-distance motion of the charge carriers. The frequency dispersions, produced by short and long -distance mobility of charge carriers, is due to the input of electrical conductivities in $\mathrm{LSNM}_{0.70} \mathrm{~T}_{0.30}$ compound, respectively.

In fact, the $\sigma_{\mathrm{dc}}$ rose with raising the temperature, indicating a semiconductor nature in the LSNM0.70 $\mathrm{T}_{0.30}$ compound.

Generally, the total electrical conductivity $\sigma(\omega)$ of the $\operatorname{LSNM}_{0.70} \mathrm{~T}_{0.30}$ sample respects Jonscher's law described as [17]:

$$
\sigma(\omega)=\sigma_{d c}+\sigma_{a c}=\sigma_{d c}+A \omega^{s}
$$

Where $A \omega^{\mathrm{s}}$ represents the transport behavior of the charge carrier within the polycrystalline compounds and ' $\mathrm{s}$ ' gives details on the level of collaboration between mobile carriers and lattice. Both parameters ' $\mathrm{A}$ ' and ' $\mathrm{s}$ ' depend on the temperature and the nature of the compound.

\subsection{1 ac conductivity study}

The experimental conductivity measurements adjusted by the equation (Eq. (1)) to determine the exponents (s) with temperature. The inset of Fig. 2(a) depicts an example of adjustment of the data for the temperature $100 \mathrm{~K}$.

Figure 2 displays the evolution of the parameter "s" which rose with temperature increase (in the range $[80 \mathrm{~K}-200 \mathrm{~K}]$ ) and then decreased in the range $[200 \mathrm{~K}-440 \mathrm{~K}]$, indicating that both conduction processes are present. So, depending on this evolution, Non-Overlapping Small 
Polaron Tunneling (NSPT) and Correlated Barrier Hopping (CBH) are the suitable models, respectively.

Similar results were found for $\mathrm{La} 0.67-\mathrm{x} \mathrm{Eu}_{\mathrm{x}} \mathrm{Ba} 0.33 \mathrm{Mn}_{0.85} \mathrm{Fe}_{0.15} \mathrm{O}_{3}$ manganites [18], $\mathrm{La} 0 .{ }_{9} \mathrm{Sr}_{0.1} \mathrm{MnO}_{3}$ ceramic [19].

For the NSPT model, the parameter "s" rose with temperature increase, in a covalent solid. The supplementing of the charge carriers to a site caused local deformation of the system. The mixture of electrons and its local deformation forms a Polaron and the energy of the states diminished via an order of $\mathrm{W}_{\mathrm{p}}$ (the Polaron Energy).

The term "Small Polaron" suggests that these particles are so focused which made their deformation clouds non-overlapping [20].

In the NSPT model, the process relates to the potential barrier $\left(\mathrm{W}_{\mathrm{H}}\right)$ between both sites. $\sigma_{\mathrm{ac}}$ is obtained from the expression [21]:

$$
\sigma_{a c}=\frac{(\pi e)^{2} k_{B} T \omega\left(N\left(E_{F}\right)\right)^{2} R_{w}^{4}}{12 \alpha}
$$

Where $\mathrm{N}\left(\mathrm{E}_{\mathrm{F}}\right), \alpha^{-1}$ and $\mathrm{R}_{\omega}$ are , respectively, the density of states close the Fermi level, the spatial extension of the polaron and the tunneling distance.

The exponent "s" may be expressed according to [22]:

$$
s=1-\frac{4 k_{B} T}{W_{H}+k_{B} T \operatorname{Ln}\left(\omega \tau_{0}\right)}
$$

Where $\mathrm{W}_{\mathrm{H}}$ is the potential barrier, $\tau_{0}(=1 / \omega=1 / 2 \pi \mathrm{f})$ is conductivity relaxation time and $\mathrm{k}_{\mathrm{B}}$ is Boltzmann's constant.

At high values of the ratio $W_{H} / k_{B} T$, Eq (3) becomes:

$$
s=1+\frac{4 k_{B} T}{W_{H}}
$$

In the CBH model, the parameter "s" decreased with temperature increase. The conduction was carried by the jump of electrons above a Coulomb barrier which divides it [23].

$\sigma_{\mathrm{ac}}$ is obtained from the expression:

$$
\sigma_{a c}=\frac{n \pi N N_{p} \varepsilon^{\prime} \varepsilon_{0} \omega R_{\omega}^{6}}{24}
$$

Where $\mathrm{n}$ is polaron number implicated in jumping behavior, $\mathrm{N}$ indicates density of localized states in which the carriers are present, $\mathrm{N}_{\mathrm{p}}$ characterizes density of localized states in which carriers jump, $\varepsilon_{0}$ indicates the dielectric constant of the free space. 
In this type of conduction, the potential barrier $\left(\mathrm{W}_{\mathrm{M}}\right)$ in the $\mathrm{CBH}$ model is described as follows [24]:

$$
s=1-\frac{6 k_{B} T}{W_{M}+k_{B} T \operatorname{Ln}\left(\omega \tau_{0}\right)}
$$

To estimate large $\mathrm{W}_{\mathrm{M}} / \mathrm{K}_{\mathrm{B}} \mathrm{T}$ values, the parameter "s" was minimized to:

$$
s=1-\frac{6 k_{B} T}{W_{M}}
$$

The $\mathrm{W}_{\mathrm{H}}$ and $\mathrm{W}_{\mathrm{M}}$ were determined from the linear adjustment of the empirical data 1-s against temperature. Their values were $\mathrm{W}_{\mathrm{H}}=0.087 \mathrm{eV}$ and $\mathrm{W}_{\mathrm{M}}=0.12 \mathrm{eV}$ (Fig. 2(b)).

In addition, as observed, temperature increase led term increase in the binding energy of the charge carriers that can hardly hop from one site to the next with more energy needed [25]

\subsection{2 de conductivity study}

$\sigma_{\mathrm{dc}}$ of the $\mathrm{LSNM}_{0.70} \mathrm{~T}_{0.30}$ sample is a concept of thermal process and according to Arrhenius' law described as follows:

$$
\sigma_{d c}=\sigma_{0} \exp \left(-\frac{E_{a}}{k_{B} T}\right)
$$

Where $\sigma_{0}$ is a pre-exponential parameter and $\mathrm{K}_{\mathrm{B}}$ is Boltzmann's constant.

The values of $E_{a}$ are determined via the slope of $\log \left(\sigma_{\mathrm{dc}} . \mathrm{T}\right)$ against 1000/T in the inset of Fig. 2(c). So , Ea values around $0.16 \mathrm{eV}$ found for conduction are very similar to these of the $\mathrm{E}_{\mathrm{a}}$ of $\mathrm{V}_{\mathrm{o}}$ in the perovskite type [26]. The transport mechanism can take place by a single or bipolaron hopping behavior over the barrier between the grain and grain boundary sites in the CBH model. The small polaron is produced from Jahn-Teller electron-phonon combination of the $\mathrm{Mn}^{3+}$ ions. On the variation of the temperature, the bipolaron can be created as the number of free carriers rises. Indeed, the rise in temperature causes an elevation in the density of free carriers, which leads to the reduction of the encountered barriers and the enhancement of conductivity [27-29]. The scaling process of conductivity spectra of LSNM0.70 $\mathrm{T}_{0.30}$ ceramic is illustrated Fig. 2(d). We can note that all the curve superimposed to produce a unique master line. The overlapping of measurements at several temperatures indicates that the process of electrical ion conduction in the $\mathrm{LSNM}_{0.70} \mathrm{~T}_{0.30}$ sample is not linked to temperature, but to a short distance attributed to the polarization of the electrode, in the low frequency interval and at high temperature.

\subsubsection{Complex impedance analysis}

The variation of the real part $\left(Z^{\prime}\right)$ of impedance against the frequency for $\operatorname{LSNM}_{0.70} \mathrm{~T}_{0.30}$ ceramic is displayed in Fig. 3(a) for a T range [80K-440K]. The magnitude of $Z^{\prime}$ is nearly independent 
of frequency, at a fixed temperature and at low frequencies, which indicates a Negative Temperature Coefficient of the Resistance [30]. In addition, the significant reduction in the magnitude of $Z^{\prime}$ with temperature rise shows the rise in the conductivity. This may be explained to improve mobility and reduced trapped charge density [31]. The evolution of $Z^{\prime}$ against the temperature gradually decreased and then disappeared by further increasing the frequencies. This behavior can validate the existence of polarization of the space charge in the $\operatorname{LSNM}_{0.70} \mathrm{~T}_{0.30}$ sample [32]. Also, we may see a shift in the plateau of $Z^{\prime}$, indicating existence of a frequency relaxation behavior in the $\mathrm{LSNM}_{0.70} \mathrm{~T}_{0.30}$ ceramic $[33,34]$.

Further investigations on the intrinsic property of the compounds were performed. The average Normalized Change (ANC) analysis is described via the following equation [35]:

$$
A N C=\frac{\Delta Z^{\prime} / \Delta f}{Z_{0}}
$$

Where $Z_{0}$ (Z' value at frequency near to zero) can be roughly evaluated via the extrapolation of the low frequency response, $\Delta Z^{\prime}=Z^{\prime}$ high- Z' low with $Z^{\prime}$ low $Z^{\prime}$ high are the $Z^{\prime}$ value at low/ high frequency $\mathrm{f}_{\text {low }} / \mathrm{f}_{\text {high }}$ and $\Delta f=\mathrm{f}_{\text {high }}-\mathrm{f}_{\text {low. }}$. The temperature dependence of the ANC is illustrated in Fig. 3(b). As expected, on rising temperature, we can see clearly that the shape of the flow curves reveals the presence of various conduction mechanisms and density of trapped charges markedly decreased. The amount of releasing trapped charge from such intrinsic defects in materials was examined by the slope of the differential of ANC. Noticeably, a modification of the slope of the differential of the ANC (inset of Fig. 3(b)), was detected around $250 \mathrm{~K}$ for LSNM $_{0.70} \mathrm{~T}_{0.30}$ ceramic.

The spectrum of impedance $\left(Z^{\prime \prime}\right)$ against the frequency at $[80 \mathrm{~K}-440 \mathrm{~K}]$ for $\mathrm{LSNM}_{0.70} \mathrm{~T}_{0.30}$ ceramic is displayed in Fig. 3(c). All data presented a peak at a specific frequency $f_{\max }$. The maximal value is indicated $Z^{\prime \prime}$ max.

The relaxation frequency $f_{\max }$ changed to the higher frequency with temperature increase, confirming presence of a relaxation behavior in temperature and frequency [26]. The relaxation time is calculated according to the equation $\tau=1 /\left(2 \pi \mathrm{f}_{\max }\right)$.

The reciprocal relationship between $\tau$ and temperature is illustrated in Fig. 3(d). The temperature connected of $\tau^{Z}$ obeys the Arrhenius' function as follows:

$$
\tau^{Z}=\tau_{0}^{Z} \exp \left(-\frac{E_{a}^{Z}}{k_{B} T}\right)
$$

Where $\mathrm{k}_{\mathrm{B}}$ is Boltzmann constant and $\tau_{0}^{Z}$ is the pre-exponential factor. 
The $E_{a}^{Z}$ values obtained via fitting of the Arrhenius graph (shown in Fig. 3(d)) are represented as $\ln \left(\tau^{Z}\right)$ as a function of $1000 / \mathrm{T}$. We remark that $E_{a}^{Z}$ is about $0.13 \mathrm{eV}$. This process is related to $\mathrm{V}_{\mathrm{o}}[36]$.

The Z"/ Z" max curve against of frequency for the LSNM0.70 $\mathrm{T}_{0.30}$ ceramic is displayed in Fig. 3(e). It is obvious that temperature evolution caused the collapse of all the lines into one line with minor differences. Thus, the repartition of the relaxation behavior can be regarded as unrelated with temperature. In addition, the Full Width at Half maximum was about 1.14. The findings indicated that the distribution of relaxation at various times is invariant and mechanism caused is a non-Debye type $[37,38]$.

Furthermore, Fig. 3(f) illustrates, at $\mathrm{T}=160 \mathrm{~K}$, curve $Z^{\prime \prime} / Z^{\prime \prime} \max _{\max }$ and $\mathrm{d}\left(Z^{\prime \prime} / Z^{\prime \prime}{ }_{\max }\right) \mathrm{df}$ for the LSNM $_{0.70} \mathrm{~T}_{0.30}$ ceramic. As seen, the position of the maximum of the data of $Z " / Z{ }^{\prime \prime} \max$ did not coincide with the position of the data of $d\left(Z^{\prime \prime} / Z^{\prime \prime}{ }_{\max }\right) / \mathrm{df}$. This shift or non-coincidence indicates the non-Debye mechanism $[37,38]$.

\subsubsection{Electric Modulus analysis}

Complex modulus $\mathrm{M}^{*}$ is calculated as follows [39]:

$$
M^{*}=M^{\prime}+j M^{\prime \prime}=j \omega C_{0} Z^{*}=\omega C_{0}\left(Z^{\prime}+j Z^{\prime \prime}\right)
$$

Where $\left(\mathrm{M}^{\prime}, \mathrm{Z}^{\prime}\right)$ and $\left(\mathrm{M}^{\prime \prime}, \mathrm{Z}^{\prime \prime}\right)$ are the real and imaginary parts of $\mathrm{M}^{*}$ and $\mathrm{Z}^{*}$, respectively; $\mathrm{C}_{0}$ is the vacuum capacitance of the measured cell and the electrodes with an air gap of the $\mathrm{LSNM}_{0.70} \mathrm{~T}_{0.30}$ ceramic thickness.

The frequency related to $\mathrm{M}^{\prime}(\omega)$ at selected temperatures $[80-440 \mathrm{~K}]$ of $\mathrm{LSNM}_{0.70} \mathrm{~T}_{0.30}$ ceramic is presented in Fig. 4(a). At low frequency, $\mathrm{M}^{\prime}(\omega)$ data tended to zero.

The appearance of the conduction behavior of short-distance mobility can account for the monotonic dispersion when raising the frequency and show the low, contribution of the electrode phenomenon [37].

Figure. 4(b) illustrates the plot of $\mathrm{M}^{\prime \prime}(\omega)$ of $\mathrm{LSNM}_{0.70} \mathrm{~T}_{0.30}$ ceramic for selected temperatures. We observed well-resolved peaks in typical frequency ( $f_{\max }$ ). In addition, the asymmetric character of $\mathrm{M}^{\prime \prime}(\omega)$ is noticed in the region of dispersion and the peak moved to the higher frequency side on raising the temperature. This suggests that the rise in relaxation with temperature increase is caused by the thermal activation of charge carriers.

Indeed, this process of thermally-activated process, the relaxation time $(\tau)$, calculated via relationship ( $2 \pi f_{\max } \tau=1$ ), is obtained from Arrhenius expression: 


$$
\tau^{M}=\tau_{0} \exp \left(-\frac{E_{a}^{M}}{k_{B} T}\right)
$$

Where $\left(\tau_{0}\right.$ and $\left.\mathrm{k}_{\mathrm{B}}\right)$ are ,respectively, pre-exponential factor and Boltzmann's constant.

$E_{a}^{M}$ was obtained via setting $\operatorname{Ln}(\tau)$ vs $1000 /$ T ( Fig. 4(c)). As expected, the reported $E_{a}^{M}$ value of the $\mathrm{LSNM}_{0.70} \mathrm{~T}_{0.30}$ ceramic was approximately the same as that obtained by measuring $\sigma(\omega)$ and in the region of those obtained for some other samples. This implies that conduction mechanism and the relaxation behavior are connected to same source.

Figure 4 (d) demonstrates the scaled coordinates $M^{\prime \prime}(\omega)$ for the spectra mentioned above, displayed on the modulus line via obtained the graph $\mathrm{M}^{\prime \prime}(\omega) / \mathrm{M}^{\prime \prime} \max (\omega)$ of the $\operatorname{LSNM}_{0.70} \mathrm{~T}_{0.30}$ sample vs the normalized frequency $\omega / \omega \max$. If all scaling curve values collapse into one main graph, them distribution of relaxation times is not influenced by the T [40].

As expected, a dispersive behavior emerged of the $\mathrm{LSNM}_{0.70} \mathrm{~T}_{0.30}$, showing that relaxation behavior for the $\mathrm{LSNM}_{0.70} \mathrm{~T}_{0.30}$ is of non-Debye process and described by presence of a polydispersive relaxation process in $\mathrm{LSNM}_{0.70} \mathrm{~T}_{0.30}$, which is in consistent with results of the IS.

\subsubsection{Dielectric results}

To evaluate the dielectric behaviors, complex permittivity $\varepsilon^{*}(\omega)$ was utilized. This latter was can be extracted from the $Z^{*}$ as [41]:

$$
\varepsilon^{*}(\omega)=\frac{1}{j C_{0} \omega Z^{*}}=\frac{Z^{\prime \prime}}{\omega C_{0}\left(Z^{\prime 2}+Z^{\prime 2}\right)}+j \frac{Z^{\prime}}{\omega C_{0}\left(Z^{\prime 2}+Z^{\prime 2}\right)}=\varepsilon^{\prime}(\omega)+j \varepsilon^{\prime \prime}(\omega)
$$

Where $\varepsilon^{\prime}(\omega), \varepsilon^{\prime \prime}(\omega)$ are the real part and the imaginary part of $\varepsilon^{*}(\omega)$, respectively.

Figure 5 (a) displays the frequency related to the $\varepsilon^{\prime}(\omega)$ at selected temperatures of $\mathrm{LSNM}_{0.70} \mathrm{~T}_{0.30}$ sample.

At low frequencies, the $\varepsilon^{\prime}(\omega)$ that tends not to be influenced by frequency exhibits colossal values that may be ascribed to the effect of the interfacial polarization achieved using Koop's theory [42], known as Maxwell-Wagner-Sillars phenomenon. Indeed, Maxwell-Wagner mechanism may be described by investigating the heterogeneity of the structure with respect to semiconductor grains divided by insulating grain boundaries with diverse electrical conductivities. Thanks to the electron jump between $\mathrm{Mn}^{3+} / \mathrm{Mn}^{4+}$, the charge carriers stuck up at the grain boundaries and created a polarization. As frequencies were increased, charge carriers reversed their orientation more frequently at grain boundary and, as a result, reduced the polarization [43]. The deformation produced by rise of temperature, at fixed frequency, can account for the reduction of the $\varepsilon^{\prime}(\omega)$ in $\operatorname{LSNM}_{0.70} \mathrm{~T}_{0.30}$ compound. The same process has been demonstrated in some sample semiconductors $[44,45]$. 
Figure 5 (b) displays the change of the frequency of $\varepsilon^{\prime \prime}(\omega)$ at several temperatures of the sample $\mathrm{LSNM}_{0.70} \mathrm{~T}_{0.30}$. As can be observed, at low frequencies, the data showed high values of $\varepsilon^{\prime \prime}(\omega)$ confirming presence of all polarization phenomena in the $\mathrm{LSNM}_{0.70} \mathrm{~T}_{0.30}$ sample.

However, as frequency increased, $\varepsilon^{\prime \prime}(\omega)$ decreased as the electric dipoles located in the LSNM0.70 $\mathrm{T}_{0.30}$ cannot follow the electric field applied to the ac [46].

It should be noted that the absence of peaks in the data of $\varepsilon^{\prime \prime}(\omega)$ suggests that the polarization mechanism in the $\mathrm{LSNM}_{0.70} \mathrm{~T}_{0.30}$ is driven via a jumping behavior as described previously [46]. In fact, $\varepsilon^{\prime \prime}(\omega)$ can be represented via the Giuntini expression provided via [47]:

$$
\varepsilon^{\prime \prime}(\omega)=a(T) \omega^{m}
$$

Where

$$
m=-4 k T / W_{c}
$$

In these equations, a ( $\mathrm{T}$ ) is a constant related only to temperature, $\mathrm{m}$ is a parameter explaining the interaction between electric dipoles, and $\mathrm{W}_{\mathrm{C}}$ is the maximum potential barrier height. We plotted the evolution of the $\operatorname{Ln}\left(\varepsilon^{\prime \prime}\right)$ v.s $\operatorname{Ln}(\omega)$ at several temperatures (in the inset of Fig.5 (c). The resulting linear graphs with slopes in the range of -1 suggest that dielectric losses are controlled by the $\sigma_{\mathrm{dc}}$ process [48].

These plots were applied to calculate the values of $\mathrm{W}_{\mathrm{c}}$ depicted in Fig.5 (d). As observed, Wc rose due to the deformation produced via temperature increase.

The similar process was found in $\operatorname{Pr}_{0.8-\mathrm{x}} \mathrm{Bi}_{\mathrm{x}} \mathrm{Sr}_{0.2} \mathrm{MnO}_{3}$ [49] , in $\mathrm{La} 0.67-\mathrm{Eu}_{\mathrm{x}} \mathrm{Ba} 0 .{ }_{33} \mathrm{Mn}_{0.85} \mathrm{Fe}_{0.15} \mathrm{O}_{3}$ [50] and in $\operatorname{Pr}_{0.5-\mathrm{x}} \mathrm{Gd}_{\mathrm{x}} \mathrm{Sr}_{0.5 \mathrm{MnO}}$ [51].

In order to verify the dominance of $\sigma_{\mathrm{dc}}$ on the dielectric properties of the $\mathrm{LSNM}_{0.70} \mathrm{~T}_{0.30}$ manganite resulting in the elimination of the relaxation behavior in $\varepsilon^{\prime \prime}(\omega)$ curve, we estimated the dielectric loss by the formula below, that is usually used at low frequencies [52]:

$$
\sigma_{A C}(\omega)=\varepsilon_{0} \omega \varepsilon^{\prime \prime}
$$

So, at low frequency, the $\varepsilon^{*}(\omega)$ is almost entirely assigned to $\sigma_{\mathrm{dc}}$. Therefore, relaxation mechanism in dielectric curves is totally obscured by $\sigma_{\mathrm{dc}}$.

\section{Conclusion}

The LSNM $_{0.70} \mathrm{~T}_{0.30}$ manganite was prepared via solid-state process. The electrical characteristics are studied by impedance spectroscopy over a wide interval of frequency and various temperatures. The complex impedance investigation reveals the presence of an electrical relaxation mechanism in the $\mathrm{LSNM}_{0.70} \mathrm{~T}_{0.30}$ sample. The $\sigma_{\mathrm{ac}}$ conductivity established that based on Jonscher law. $\sigma_{\mathrm{ac}}$ is described at low temperatures by Non-overlapping Small 
Polaron Tunneling model and at high temperatures Correlated Barrier Hopping model. From dc conductance measurement, the electronic conduction appears to be thermally activated, suggesting the existence of semiconductor behavior. Additionally, the dielectric constant curves were applied to study the relaxation dynamics of charge carriers. In fact, Debye-like relaxation was interpreted using the polarization of spatial charges following Maxwell-Wagner model and Koop's phenomenological theory.

\section{Reference}

1. S. EL. Kossi, S. Mnefgui, J. Dhahri, E. K. Hlil, The coexistence of cluster glass behavior and long-range ferromagnetic ordering in $\mathrm{La}_{0.7} \mathrm{Sr}_{0.25} \mathrm{Na}_{0.05} \mathrm{Mn}_{0.7} \mathrm{Ti}_{0.3} \mathrm{O}_{3}$ manganite, Ceram Int., 41, 8331-8340 (2015). https://doi.org/10.1016/j.jssc.2015.08.027

2. M. Smari, R. Hamdi, S. Slimani, A. Bajorek, D. Peddis, I. Walha, U. Koneva, E. Dhahri, and Y. Haik, Enhancement of the Magnetotransport Behavior in a Phase-Separated $\mathrm{LaAgCaMnO}_{3}$ Polycrystalline: Unraveling the Role of a Multi-Double-Exchange Mechanism, J. Phys. Chem. C 124, 23324-23332 (2020). https://doi.org/10.1021/acs.jpcc.0c06661.

3. M Smari, R Hamouda, I Walha, E Dhahri, FJ Mompeán, Mar García-Hernández, Magnetic and magnetoresistance in half-doped manganite $\mathrm{La} 0.5 \mathrm{Ca} 0.5 \mathrm{MnO}_{3}$ and $\mathrm{La} 0.5 \mathrm{Ca}$ ${ }_{0.4} \mathrm{Ag}_{0.1} \mathrm{MnO}_{3} \quad$, J. Alloys Compd, 644, 632-637 (2015). https://doi.org/10.1016/j.jallcom.2015.05.026

4. M. Smari, R. Hamdi, E. Dhahri, E.K. Hlil, L. Bessais, Correlation between magnetic and electric properties of $\mathrm{La}_{0.5} \mathrm{Ca} \mathrm{Ca}_{3} \mathrm{Ag}_{0.2} \mathrm{MnO}_{3}$ based on critical behavior of resistivity, Ceram Int, 42,10405-10409 (2016). https://doi.org/10.1016/j.ceramint.2016.03.182.

5. I. Walha, M. Smari, T. Mnasri, E .Dhahri, Structural, magnetic, and magnetocaloric properties of Ag-doped in the $\mathrm{La} 0.6 \mathrm{Ca} 0.4 \mathrm{MnO}_{3}$ compound, J. Magn. Magn. Mater, 454 ,190-195 (2018). https://doi.org/10.1016/j.jmmm.2018.01.084

6. R Hamdi, A Tozri, M Smari, K Nouri, E Dhahri, L Bessais, Structural, magnetic and AC susceptibility properties of $\mathrm{Dy}_{0.5}\left(\mathrm{Sr}_{1-\mathrm{x}} \mathrm{Ca}_{\mathrm{x}}\right)_{0.5} \mathrm{MnO}_{3}(0 \leq \mathrm{x} \leq 0.3)$ manganites, J. Mol. Struct , 1175, 844-851 (2019). https://doi.org/10.1016/j.molstruc.2018.08.052.

7. S. EL. Kossi, Ch. Rayssi, AH. Dhahri, J. Dhahri and K. Khirouni, High dielectric constant and relaxor behavior in $\mathrm{La}_{0.7} \mathrm{Sr}_{0.25} \mathrm{Na}_{0.05} \mathrm{Mn}_{0.8} \mathrm{Ti}_{0.2} \mathrm{O}_{3}$ manganite, J. Alloys Compd, 767 ,456-463(2018). https://doi.org/10.1016/j.jallcom.2018.07.056

8. F.B. Abdallah, A. Benali, M. Triki, E. Dhahri, M.P.F. Graça, M.A. Valente, Effect of annealing temperature on structural, morphology and dielectric properties of La0.75 
$\mathrm{Ba}_{0.25} \mathrm{FeO}_{3}$ perovskite, J. Superlattice. Microst 117, 260-270 (2018). https://doi.org/10.1016/j.spmi.2018.03.048

9. B. Padmanabhan, S. Elizabeth, H.L. Bhat, S. Robler, K. Dorr, K.H. Muller, Crystal growth, transport and magnetic propertiesof rare-earth manganite $\operatorname{Pr}_{1-\mathrm{x}} \mathrm{Pb}_{\mathrm{x}} \mathrm{MnO}_{3}, \mathrm{~J}$. $\begin{array}{lllll}\text { Magn. } & \text { Magn. } & \text { Mater } & \text { (2006). }\end{array}$ https://doi.org/10.1016/j.jmmm.2006.04.018

10. Z. Raddaoui, ,R. Lahouli, S.E.L. Kossi, J. Dhahri, K. Khirouni, K. Taibi, Structural and thermoelectric properties of $\mathrm{Ba} 0.97 \mathrm{Nd}_{0.0267} \mathrm{Ti}_{0.95} \mathrm{~W}_{0.05} \mathrm{O}_{3}$ ceramic, J. Alloys Compd, 765, 428-436 (2018). https://doi.org/ 10.1016/j.jallcom.2018.06.180

11. V. P. Kumar, V. Dayal, R. L. Hadimani, R. N. Bhowmik and D. C. Jiles, Magnetic and electrical properties of Ti-substituted lanthanum bismuth manganites, J. Mater. Sci, 50, 3562-3575(2015). https://doi.org/10.1007/s10853-015-8916-1

12. H. Ghoudi, S. Chkoundali, Z. Raddaoui, A. Aydi, Structure properties and dielectric relaxation of $\mathrm{Ca} 0.1 \mathrm{Na} 0.9 \mathrm{Ti}_{0.1} \mathrm{Nb}_{0.9} \mathrm{O}_{3}$ ceramic, RSC Adv, 9, 25358-25367 (2019). https://doi.org/10.1039/c9ra03967h.

13. M. Bourguiba, Z. Raddaoui, M. Chafra and J. Dhahri, The investigation of structural and vibrational properties and optical behavior of Ti-doped $\mathrm{La} 0.67 \mathrm{Ba} 0.25 \mathrm{Ca} 0.08 \mathrm{Mn}$ (1x) $\mathrm{Ti}_{\mathrm{x}} \mathrm{O}_{3}$ ( $\mathrm{x}=0.00,0.05$ and 0.10) manganites, RSC Adv.,9, 42252 (2019). https://doi.org/10.1039/c9ra07407d.

14. Z. Raddaoui, R. Lahouli, S. El Kossi, J. Dhahri, H. Belmabrouk, H, A. Bajahzar, Study of conduction mechanism, electrical property, and nonlinear electrical behaviors of $\mathrm{Ba} 0.97 \mathrm{Bi}_{0.02} \mathrm{Ti}_{0.9} \mathrm{Zr}_{0.05} \mathrm{Nb}_{0.04} \mathrm{O}_{3}$ perovskite, J. Mater. Sci.: Mater. 31, 4836-4849 (2020). https://doi.org/ 10.1007/s10854-020-03046-X

15. S.EL. Kossi, S. Ghodhbane, S. Mnefgui, J. Dhahri, E.K. Hlil, The impact of disorder on magnetocaloric properties in Ti-doped manganites of $\mathrm{La}_{0.7} \mathrm{Sr}_{0.25} \mathrm{Na} 0.05 \mathrm{Mn}(1-\mathrm{x}) \mathrm{Ti}_{\mathrm{x}} \mathrm{O}_{3}$ $(0 \leq x \leq 0.2)$ J. Magn. Magn. Mater, 395, 134-142 (2015). https://doi.org/10.1016/j.jmmm.2015.07.050

16. S. EL. Kossi, J. Dhahri and E.K. Hlil, The coexistence of cluster glass behavior and long-range ferromagnetic ordering in $\mathrm{La} 0.7 \mathrm{Sr} 0.25 \mathrm{Na} 0.05 \mathrm{Mn}_{0.7} \mathrm{Ti}_{0.3} \mathrm{O}_{3}$ manganite, J. Solid State Chem, 231, 248-255 (2015). https://doi.org/10.1016/j.jssc.2015.08.027

17. Z. Raddaoui, S. E. L. Kossi, T. Al-shahrani, M. Bourguiba, J. Dhahri, M. Chafra, H. Belmabrouk, Study of structural, conduction mechanism and dielectric behavior of La ${ }_{0.7} \mathrm{Sr}_{0.3} \mathrm{Mn}_{0.8} \mathrm{Fe}_{0.2} \mathrm{O}_{3}$ manganite, J. Mater. Sci.: Mater, 31, 21732-21746 (2020). https://doi.org/10.1007/s10854-020-04686-9 
18. W. Ncib , A. Ben Jazia Kharrat, M. A. Wederni, N. Chniba-Boudjada, K. Khirouni, W. Boujelben, Investigation of structural, electrical and dielectric properties of sol-gel prepared La0.67-x $\mathrm{Eu}_{\mathrm{x}} \mathrm{Ba} 0.33 \mathrm{Mn}_{0.85} \mathrm{Fe}_{0.15} \mathrm{O}_{3}$ (x=0.0, 0.1) manganites, J. Alloys Compd, 768 , 249-262 (2018). https://doi.org/10.1016/j.jallcom.2018.07.192

19. W. Hizi, H. Rahmouni, M. Gassoumi, K. Khirouni, S. Dhahri, Transport properties of La0.9Sro.1 $\mathrm{MnO}_{3}$ manganite, Eur. Phys. J. Plus, 135. 456 (2020). https://doi.org/10.1140/epjp/s13360-020-00492-8

20. S. Halder, A. Duttab and T. P. Sinha, Time-temperature superposition in the grain and grain boundary response regime of $\mathrm{A}_{2} \mathrm{HoRuO}_{6}(\mathrm{~A}=\mathrm{Ba}, \mathrm{Sr}, \mathrm{Ca})$ double perovskite ceramics: a conductivity spectroscopic analysis, RSC Adv., 7, 43812 (2017). https://doi.org/10.1039/C7RA08295A.

21. A. Zaafouri, M. Megdiche, Experimental and theoretical study of AC electrical conduction mechanisms by NSPT model of $\mathrm{LiNa}_{3-\mathrm{x}} \mathrm{Ag}_{\mathrm{x}} \mathrm{P}_{2} \mathrm{O}_{7}(\mathrm{x}=0.2$ and 0.6$)$ ceramic compounds, Ionics , 23, 1155-1164 (2017) . https://doi.org/10.1007/s11581-016-19353

22. A.R. Long, Frequency-dependent loss in amorphous semiconductors, Adv. Phys., 31, 553-637 (1982). https://doi.org/10.1080/00018738200101418

23. B. Panda, K. Lokapriya Routray, D. Behera, Studies on conduction mechanism and dielectric properties of the nano-sized $\mathrm{La}_{0.7} \mathrm{Ca} 0.3 \mathrm{MnO}_{3}$ (LCMO) grains in the paramagnetic state, Phys. B Condens. Matter, 583, 411967(2020). https://doi.org/10.1016/j.physb.2019.411967

24. M. Ben Bechir, K. Karoui, M. Tabellout, K. Guidara, A. Ben Rhaiem, Alternative current conduction mechanisms of organic-inorganic compound $\left[\mathrm{N}\left(\mathrm{CH}_{3}\right)_{3} \mathrm{H}\right]_{2} \mathrm{CuCl}_{4}, \mathrm{~J}$. Appl. Phys, 115, 203712(2014). https://doi.org/10.1063/1.4880735.

25. I. S. Debbebi, S. M. Borchani, W. C. Koubaa, and A. Cheikhrouhou, Study of complex impedance spectroscopic properties of $\mathrm{La}_{0.7-\mathrm{x}} \mathrm{Dy}_{\mathrm{x}} \mathrm{Sr}_{0.3} \mathrm{MnO}_{3}$ perovskite oxides, $\mathrm{R} \mathrm{Soc}$ Open Sci. 5, 172201 (2018). https://doi.org/10.1098/rsos.172201.

26. M. Bourguiba, Z. Raddaoui, A. Dhahri, M. Chafra, J. Dhahri, M.A. Garcia, Investigation of the conduction mechanism, high dielectric constant, and non-Debyetype relaxor in $\mathrm{La}_{0.67} \mathrm{Ba}_{0.25} \mathrm{Ca}_{0.08} \mathrm{MnO}_{3}$ manganite, J. Mater. Sci.: Mater, 31, 1181011818 (2020). https://doi.org/10.1007/s10854-020-03733-9.

27. M. Sassi, A. Bettaibi, A. Oueslati, K. Khirouni, M. Gargouri, Electrical conduction mechanism and transport properties of LiCrP2O7 compound, J. Alloy. Compd, 649 , 642-648 (2015). https://doi.org/10.1016/j.jallcom.2015.07.148. 
28. S.A. Mansour, I.S. Yahia, F. Yakuphanoglu, The electrical conductivity and dielectric properties of C.I. Basic Violet 10, Dyes Pigm, 87 , 144-148 (2010). https://doi.org/10.1016/j.dyepig.2010.03.011.

29. Z. Raddaoui, S. El Kossi, B. Smiri, T. Al-Shahrani, J. Dhahri, H. Belmabrouk, Raman scattering and red emission of $\mathrm{Mn}^{4+}$ in $\mathrm{La} 0.7 \mathrm{Sr} 0.25 \mathrm{Na} 0.05 \mathrm{Mn} 0.7 \mathrm{Ti}_{0.3} \mathrm{O}_{3}$ manganite phosphor for LED applications, RSC Adv, 10, 23615-23623 (2020). https://doi.org/10.1039/d0ra04033a

30. M. Atif, M. Nadeem, W. Khalid, Z. Ali, Structural, magnetic and impedance spectroscopy analysis of $(0.7) \mathrm{CoFe}_{2} \mathrm{O}_{4}+(0.3) \mathrm{BaTiO}_{3}$ magnetoelectric composite, Mater. Res. Bull, 107, 171-179(2018). https://doi.org/10.1016/j.materresbull.2018.07.026.

31. L. Singh, I.W. Kim, B.C. Sin, A. Ullah, S.K. Woo, Y. Lee, Study of dielectric, ACimpedance, modulus properties of $0.5 \mathrm{Bi} 0.5 \mathrm{Na}_{0.5} \mathrm{TiO}_{3} \cdot 0.5 \mathrm{CaCu}_{3} \mathrm{Ti}_{4} \mathrm{O}_{12}$ nano-composite synthesized by a modified solid state method, J. Mater. Sci. Semicond. Process, 31, 386396 (2015). https://doi.org/10.1016/j.mssp.2014.12.025

32. M Smari, H Felhi, R Hamdi, K Nouri, E Dhahri, L Bessais, Correlation between structural, magnetic and electric properties of $\mathrm{La} 0.5 \mathrm{Ca} 0.3 \mathrm{Te}_{0.2} \mathrm{MnO}_{3}$ sample synthesis by sol-gel method, Chemical Physics Letters 684, 72-78 (2017). https://doi.org/10.1016/j.cplett.2017.06.038

33. I. Coondoo, N. Panwar, R. Vidyasagar, A.L. Kholkin, Defect chemistry and relaxation processes: effect of an amphoteric substituent in lead-free BCZT ceramics, Phys. Chem. Chem. Phys, 18 , 31184-31201(2016). https://doi.org/10.1039/C6CP06244J.

34. K. Cherif, A. Belkhla, J. Dhahri, Impedance studies of $\mathrm{La}_{0.6} \mathrm{Gd}_{0.1} \mathrm{Sr}_{0.3} \mathrm{Mn}_{0.9} \mathrm{In}_{0.1} \mathrm{O}_{3}$ manganite prepared by the sol-gel method, J. Alloys Compd, 777 ,358-363(2019). https://doi.org/10.1016/j.jallcom.2018.11.032.

35. Z. Raddaoui , S. El Kossi, B. Smiri, A. Maaoui, J. Dhahri, R. M'Ghaieth, N. Abdelmoula, K. Khirouni, Correlation of crystal structure and optical properties of Ba0.97Nd0.0267 $\operatorname{Ti}(1-x) \mathrm{W}_{\mathrm{x}} \mathrm{O}_{3}$ perovskite, RSC Adv, 8, 27870-27880 (2018). https://doi.org/ $10.1039 / \mathrm{c} 8 \mathrm{ra05302b}$

36. N. Othmani, A. Amouri, F. Benabdallah, Z. Sassi, L. Seveyrat, L. Lebrun, V. Perrin, H. Khemakhem, Effect of bismuth doping on structural and electrical properties of 0.9 $\left(\mathrm{BaZr}_{0.2} \mathrm{Ti}_{0.8} \mathrm{O}_{3}\right)-0.1\left(\mathrm{Ba}_{0 .} \mathrm{Ca}_{0.3} \mathrm{TiO}_{3}\right)$ ceramic, Ceram. Int, 46 22592-22605(2020). https://doi.org/10.1016/j.ceramint.2020.06.020 
37. S.E.L. Kossi, F.I.H. Rhouma, J. Dhahri, K. Khirouni, Structural and electric properties of La0.7 $\mathrm{Sr}_{0.25} \mathrm{Na} 0.05 \mathrm{Mn}_{0.9} \mathrm{Ti}_{0.1} \mathrm{O}_{3}$ ceramics, ,J Mater Sci: Mater Electron ceramics. Phys. B, 440, 118-123 (2014). https://doi.org/10.1016/j.physb.2014.01.016

38. B.N. Parida, R. Padhee, D. Suara, A. Mishra, R.N.P. Choudhary, Dielectric relaxation and impedance analysis of ferroelectric double perovskite $\mathrm{Pb}_{2} \mathrm{BiNbO}_{6}$, J. Mater. Sci. Mater. Electron, 28 , 1824-1831 (2017). https://doi.org/ 10.1007/s10854-016-5732-6

39. K. Lily, K. Kumari, K. Prasad, R.N.P. Choudhary, Impedance spectroscopy of $\left(\mathrm{Na} 0.5 \mathrm{Bi}_{0.5}\right)\left(\mathrm{Zr}_{0.25} \mathrm{Ti}_{0.75}\right) \mathrm{O}_{3}$ lead-free ceramic, J. Alloys Compd,, 453, 325-331(2008). https://doi.org/10.1016/j.jallcom.2006.11.081.

40. N.S. Rani, R.P. Ahlawat, K.M. Sangwan, P. Khandewal, Dielectric and impedance studies of $\mathrm{La}$ and $\mathrm{Zn}$ co-doped complex perovskite $\mathrm{CaCu}_{3} \mathrm{Ti}_{4} \mathrm{O}_{12}$ ceramic. Ceram. Int. 44, 23125-23136 (2018). https://doi.org/10.1016/j.ceramint.2018.09.121

41. C.L. Du, S.T. Zhang, G.X. Cheng, M.H. Lu, Z.B. Gu, J. Wang, Y.F, Compositiondependent structures and properties of $\mathrm{Bi}_{4} \mathrm{Ti}_{3-\mathrm{x}} \mathrm{Zr}_{\mathrm{x}} \mathrm{O}_{12}$ ceramics, Chen, Phys $\mathrm{B} 368$,157162 (2005). https://doi.org/10.1016/j.physb.2005.07.011

42. C. Ang, Z. Yu, L.E. Cross, Oxygen-vacancy-related low-frequency dielectric relaxation and electrical conduction in $\mathrm{Bi}: \mathrm{SrTiO}_{3}$ Phys. Rev. B , 62 ,228 (2000). https://doi.org/10.1103/PhysRevB.62.228.

43. S. Sil, J. Datta, M. Das, R. Jana, S. Halder, A. Biswas, D. Sanyal, P.P. Ray, Bias dependent conduction and relaxation mechanism study of Cu5FeS4 film and its significance in signal transport network, J. Mater. Sci. 29, 5014-5024 (2018). https://doi.org/10.1007/s10854-017-8463-4

44. M. Atif, M. Idrees, M. Nadeem, M. Siddique, M.W. Ashraf, Investigation on the structural, dielectric and impedance analysis of manganese substituted cobalt ferrite ie, $\mathrm{Co}_{1-\mathrm{x}} \mathrm{Mn}_{\mathrm{x}} \mathrm{Fe}_{2} \mathrm{O}_{4} \quad(0.0 \leq \quad \mathrm{x} \quad \leq 0.4), \quad \mathrm{RSC} \quad \mathrm{Adv}, \quad$ 6, $2087 \quad$ (2016). https://doi.org/10.1039/C5RA20621A

45. H. Rahmouni, R. Jemai, M. Nouiri, N. Kallel, F. Rzigua, A. Selmi, K. Khirouni, S. Alaya, Admittance spectroscopy and complex impedance analysis of Ti-modified La0.7 $\mathrm{Sr}_{0.3} \mathrm{MnO}_{3}$, J. $\quad$ Cryst. $310 \quad$ 556-561 (2008). https://doi.org/10.1016/j.jcrysgro.2007.11.027

46. W. Wan, J. Luo, C.-E. Huang, J. Yang, Y. Feng, W.-X. Yuan, Y. Ouyang, D. Chen, T. Qiu, Calcium copper titanate/polyurethane composite films with high dielectric constant, low dielectric loss and super flexibility, Ceram. Int, 44 (2018) 5086-5092. https://doi.org/10.1016/j.ceramint.2017.12.108 
47. J.C. Giuntini, J.V. Zanchetta, D. Jullien, R. Eholie, P.J. Houenou, Temperature dependence of dielectric losses in chalcogenide glasses, J. Non-Cryst. Solids, 45, 5762(1981). https://doi.org/10.1016/0022-3093(81)90089-2

48. A. Daidouh, M.L. Veiga, C. Pico, Structure determination of the new layered compound $\mathrm{Cs}_{2} \mathrm{TiP}_{2} \mathrm{O}_{8}$ and ionic conductivity of $\mathrm{Cs}_{2} \mathrm{MP}_{2} \mathrm{O}_{8}(\mathrm{M}=\mathrm{Ti}, \mathrm{V})$, Solid State Ion. 104 , $285-$ 294 (1997). https://doi.org/10.1016/S0167-2738(97)00412-8

49. A.B.J. Kharrat, S. Moussa, N. Moutiaa, K. Khirouni, W. Boujelben, Structural, electrical and dielectric properties of Bi-doped $\operatorname{Pr}_{0.8-\mathrm{x}} \mathrm{Bi}_{\mathrm{x}} \mathrm{Sr}_{0.2} \mathrm{MnO}_{3}$ manganite oxides prepared by sol-gel process, J. Alloys Compd, 724,389-399 (2017). https://doi.org/10.1016/j.jallcom.2017.07.046.

50. W. Ncib, A.B.J. Kharrat, M.A. Wederni, N. Chniba- Boudjada, K. Khirouni, W. Boujelben, Investigation of structural, electrical and dielectric properties of sol-gel prepared $\mathrm{La}_{0.67-\mathrm{x}} \mathrm{Eu}_{\mathrm{x}} \mathrm{Ba} 0.33 \mathrm{Mn}_{0.85} \mathrm{Fe}_{0.15} \mathrm{O}_{3}(\mathrm{x}=0.0,0.1$ ) manganites, J. Alloys Compd, 768, 249-262(2018) . https://doi.org/10.1016/j.jallcom.2018.07.192.

51. A.Ben Jazia Kharrat, M. Bourouina, N. Moutia, K. Khirouni, W. Boujelben, Gd doping effect on impedance spectroscopy properties of sol-gel prepared $\operatorname{Pr}_{0.5-\mathrm{x}} \mathrm{Gd}_{\mathrm{x}} \mathrm{Sr}_{0.5} \mathrm{MnO}_{3}$ $(0 \leq \mathrm{x} \leq 0.3) \quad$ perovskites, J. Alloys Compd, 741, 723-733(2018). https://doi.org/10.1016/j.jallcom.2018.01.236.

52. D.E. Y1ld1z, I. Dokme, Frequency and gate voltage effects on the dielectric properties and electrical conductivity of $\mathrm{Al} / \mathrm{SiO}_{2} / \mathrm{p}$-Si metal-insulator-semiconductor Schottky diodes, J. Appl. Phys, 110, 014507(2011). https://doi.org/10.1063/1.3602090 
Figures

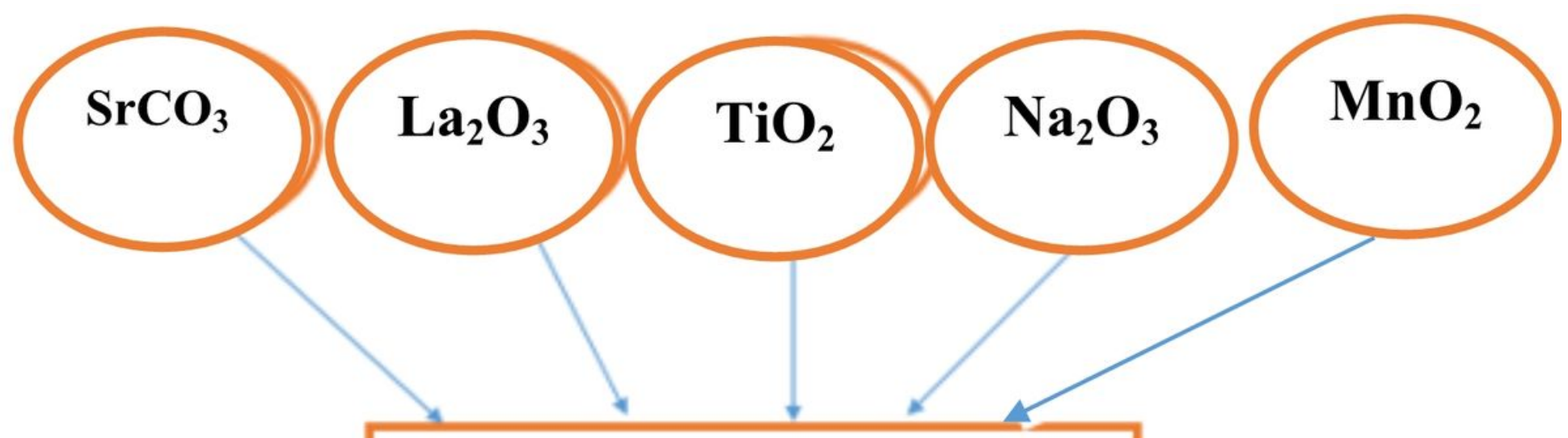

\section{Dehydration of precursors}

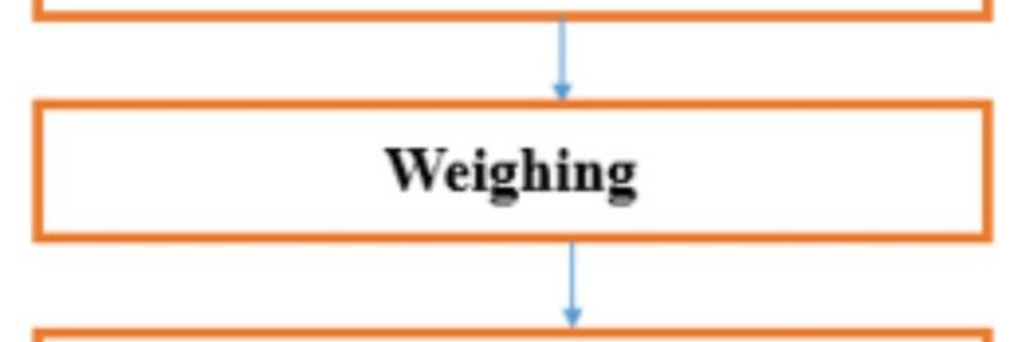

Mixing and grinding

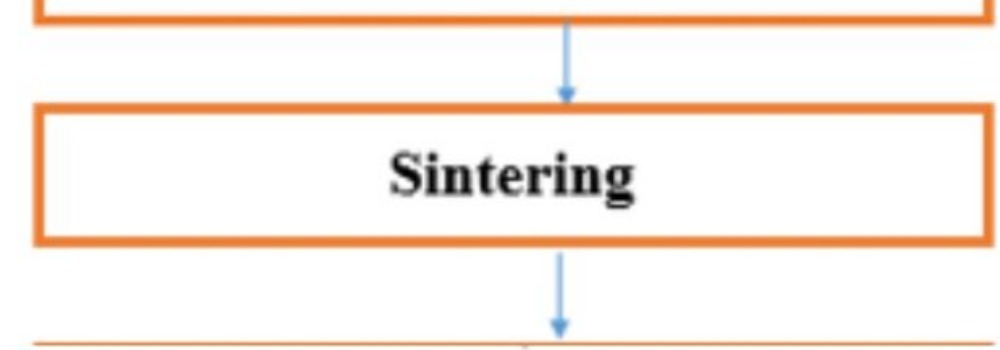

\section{Calcination}

Figure 1

Flowchart diagram for the preparation of LSNM0.70T0.30 sample. 

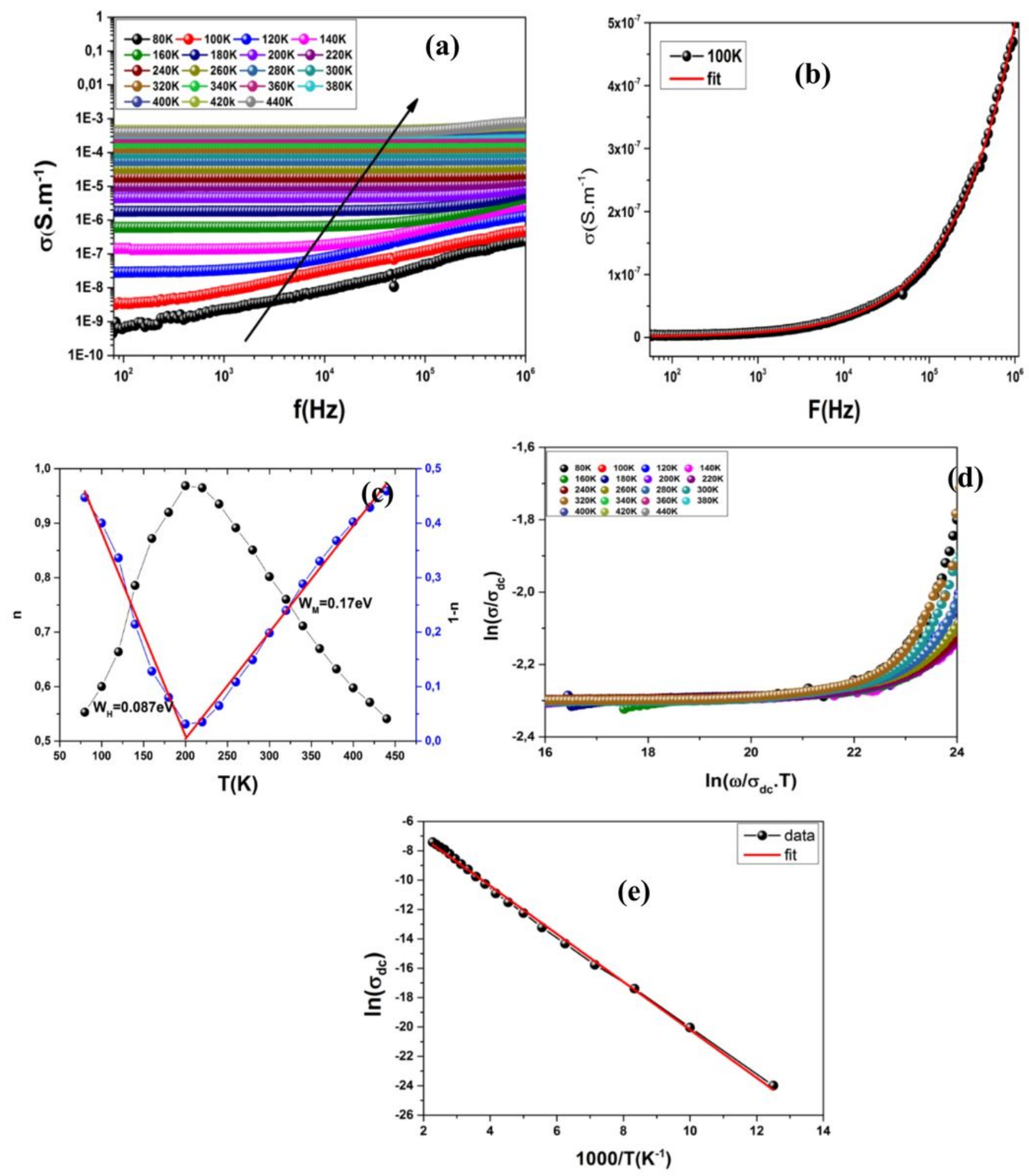

\section{Figure 2}

Electrical conductivity behavior of the LSNM0.70T0.30 sample. (a) Frequency dependence of the electrical conductivity at several temperatures. Inset: Variation of the dc component versus the temperature. (b) Comparison of the experimental data and theoretical fit curve for the temperature $280 \mathrm{~K}$. Inset: the variation of the exponents s and (1-s) with temperature. (c) Variation of Log (odcT) vs 1000/T. (d) Reduced conductivity. 

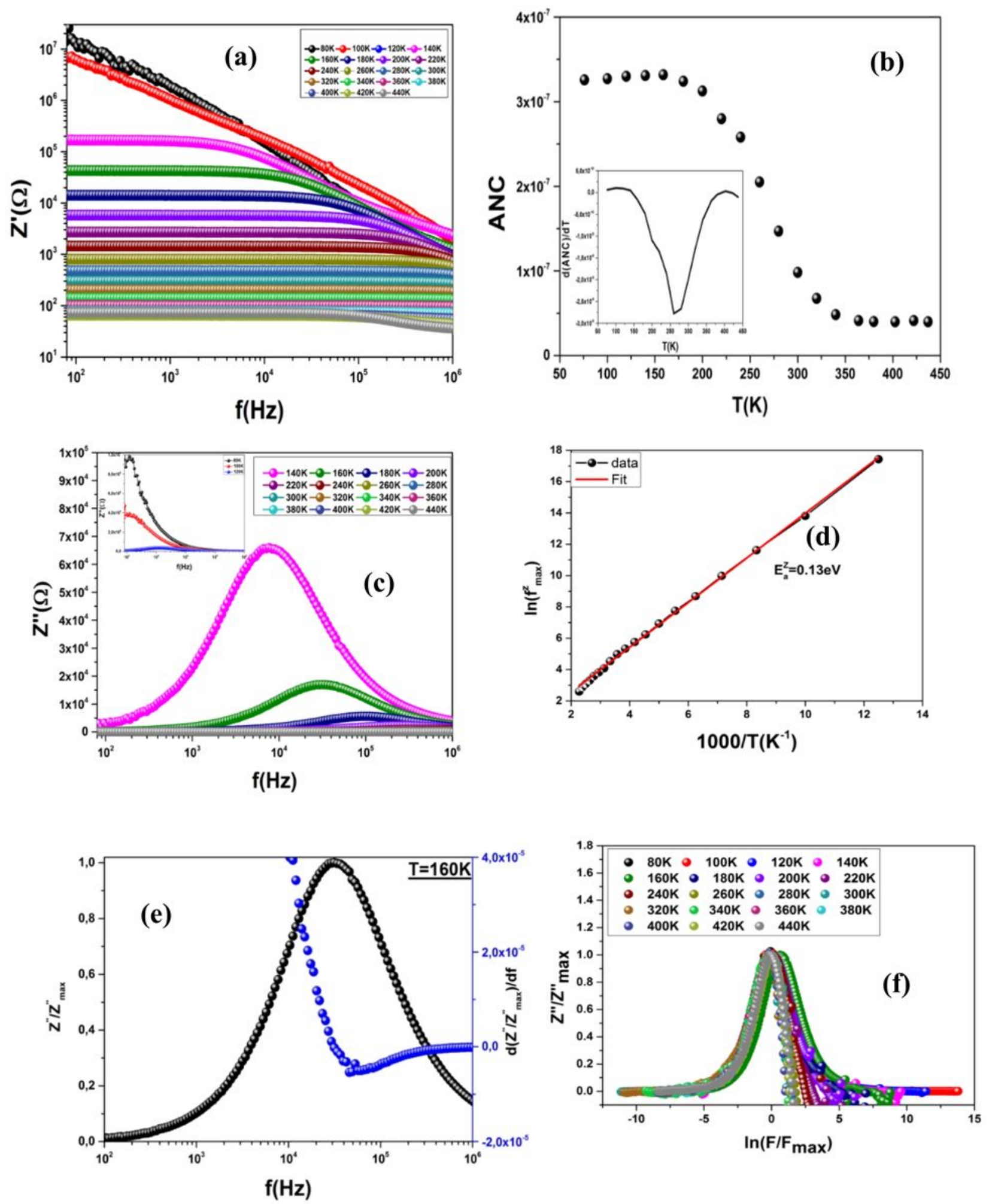

Figure 3

(a) Spectra of the real part of impedance ( $\left.Z^{\prime}\right)$, (b) the ANC of LSNM0.70T0.30 ceramic, (c) Spectra of the impedance (Z"), (d) Computation of the activation energy, (e) Variation of Z"/Z"max versus $\mathrm{f} / \mathrm{fmax}$ for

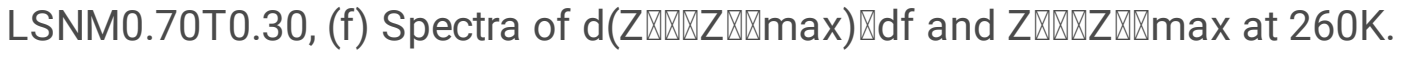



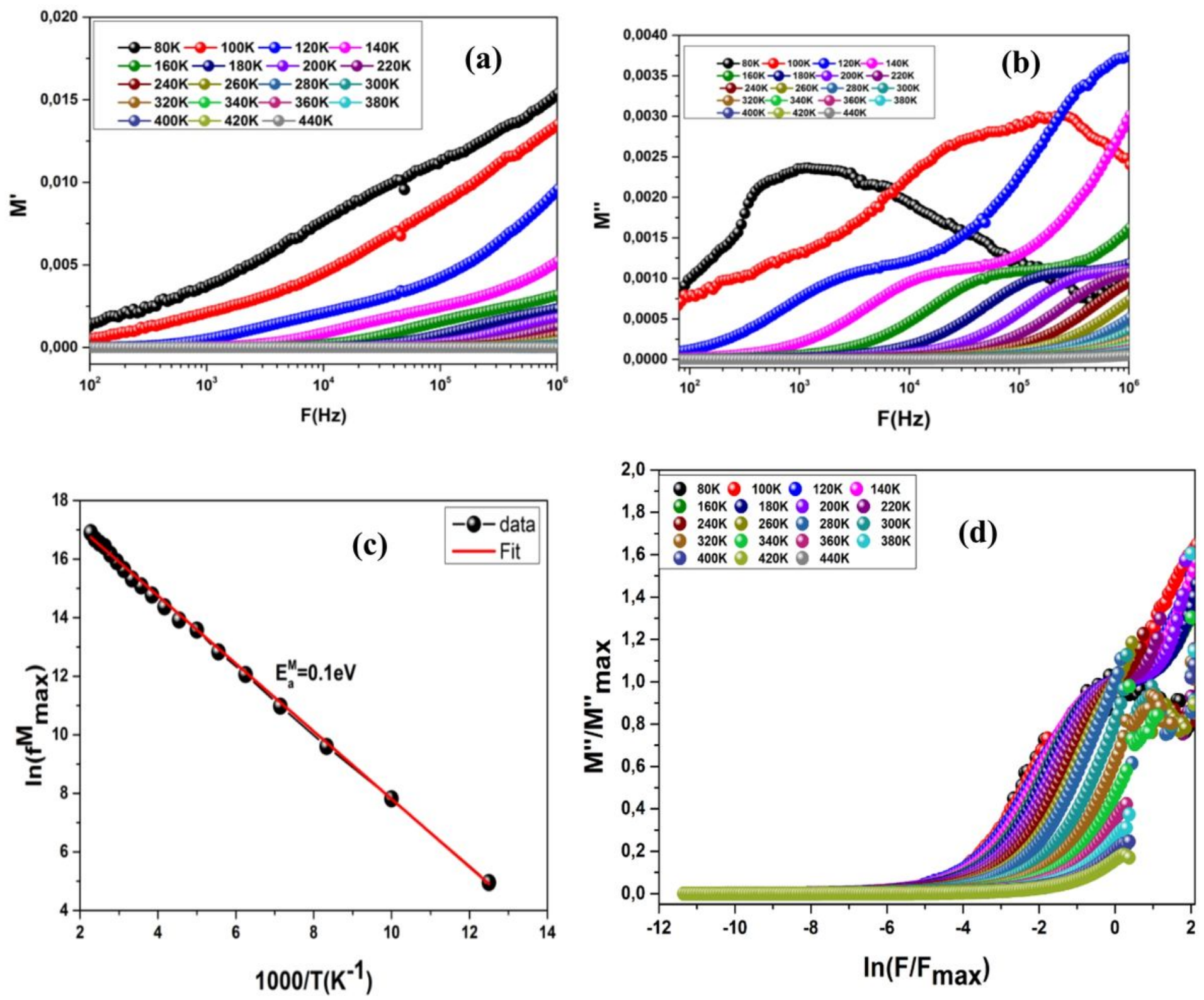

Figure 4

(a) Spectra of the real part (M') of the complex modulus, (b) Spectra of the imaginary part (M") of complex modulus, (c) Relaxation time versus the inverse of T, (d) Reduced electrical modulus vs the reduced frequency of LSNM0.70T0.30 ceramic. 

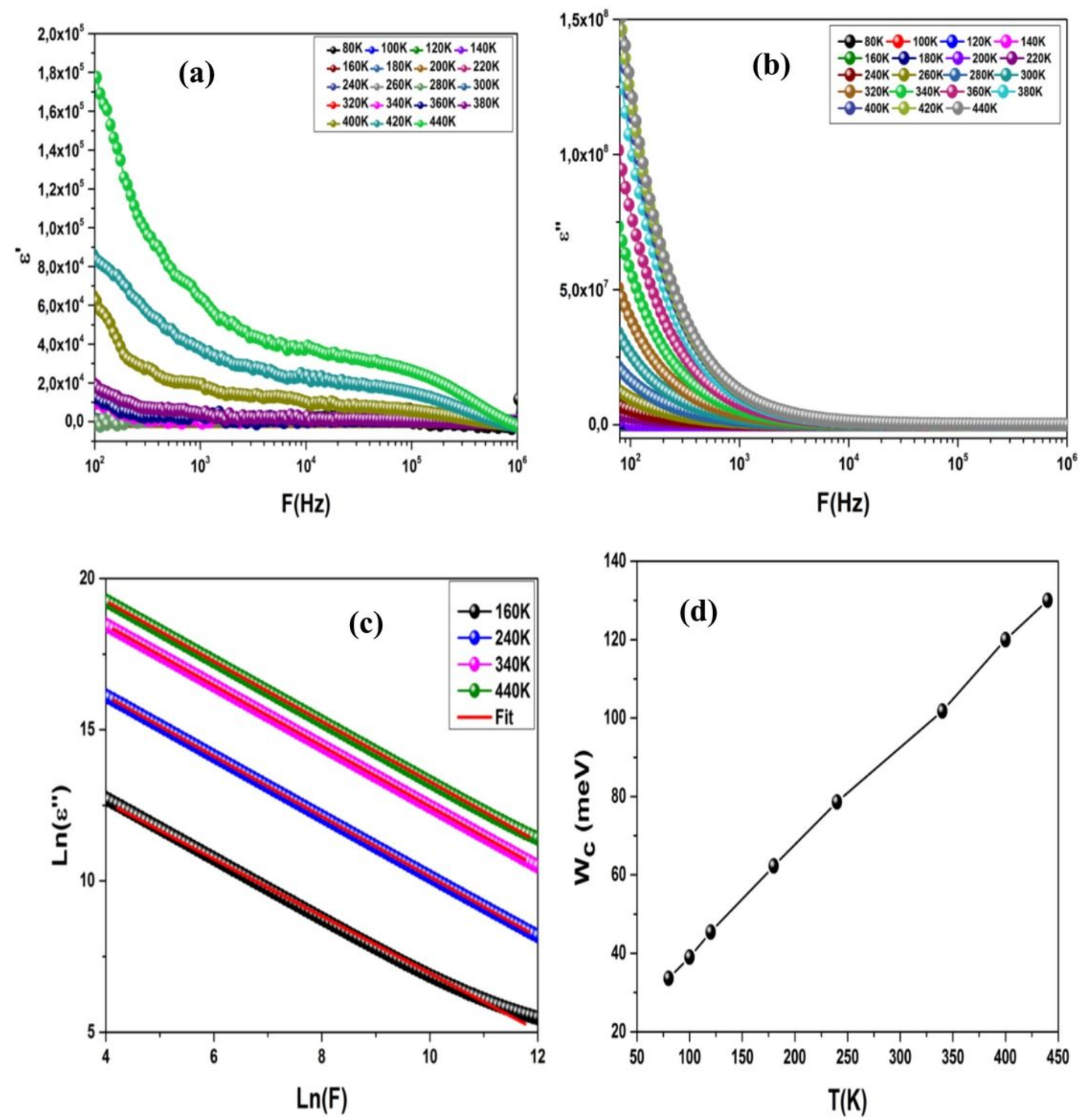

Figure 5

(a) Spectra of the permittivity $\varepsilon^{\prime}$, (b) Spectra of the permittivity $\varepsilon^{\prime \prime}$, (c) Evolution of $\operatorname{Ln}\left(\varepsilon^{\prime \prime}\right)$ versus $\operatorname{Ln}(\omega)$ for LSNM0.70T0.30, (d) Evolution of the energy Wc at different temperatures for LSNM0.70T0.30 ceramic. 